\title{
Topic Maintenance and Topic Transition in a Couple's Dinnertime Conversation
}

\author{
Saleh Batais ${ }^{1}$ \\ ${ }^{1}$ Department of English Language \& Literature, College of Arts, King Saud University, Riyadh, Saudi Arabia \\ Correspondence: Saleh Batais, Department of English Language \& Literature, College of Arts, King Saud \\ University, Riyadh, Saudi Arabia. E-mail: sbatais@ksu.edu.sa
}

Received: June 18, 2019 Accepted: July 10, 2019 Online Published: August 26, 2019

doi:10.5539/ijel.v9n5p267 URL: https://doi.org/10.5539/ijel.v9n5p267

\begin{abstract}
This paper investigates the patterns of topic maintenance and topic transition used to create conversation and their accompanying structural features speakers employ to signal these two conversational phenomena. The data are a 21-minute dyadic dinnertime conversation between a boyfriend and girlfriend; they are both native speakers of American English, in their late twenties. The two significant findings of the study are as follows. First, the data reveal that the speakers used three major techniques, namely minimal responses, substitutions, and deletions, to maintain the same topic of the conversation (Goffman, 1983; Radford \& Tarplee, 2000; Abu Akel, 2002; Sukrutrit, 2010; Jeon, 2012). Second, in the analysis of topic transition, the data show that the speakers resorted to different types of topic transitions (i.e., collaborative, unilateral, linked, minimally linked, and sudden) to end an ongoing topic and start a new one (West \& Garcia, 1988; Ainsworth-Vaughn, 1992; Okamoto \& Smith-Lovin, 2001; Sukrutrit, 2010; Jeon, 2012).
\end{abstract}

Keywords: conversational analysis, dyad, topic maintenance, topic transition

\section{Introduction}

The notion of topic as a discourse unit of analysis has received major attention from linguists (e.g., Li \& Thompson, 1976; Roberts, 2011; Zellers, 2013) and conversation analysts (e.g., Schegloff \& Sacks, 1973; Schegloff, 1979; Holt \& Drew, 2005; Sidnell, 2010; Sukrutrit, 2010). Although the subject is clearly of considerable importance to discourse theory (Brown \& Yule, 1983), little attention has been paid to the issues of topic maintenance and topic transition in a couple's conversations. This paper deals with the dynamics of topic maintenance and topic transition in dinnertime conversations and examines what markers participants employ to signal these two conversational phenomena. With respect to topic maintenance, it was found that the speakers used three major techniques: minimal responses, substitutions, and deletions (Goffman, 1983; Radford \& Tarplee, 2000; Abu Akel, 2002; Sukrutrit, 2010; Jeon, 2012). The data, moreover, confirmed the types of topic transitions (i.e., collaborative, unilateral, linked, minimally linked, and sudden) and their accompanying features, as discussed in West and Garcia (1988), Ainsworth-Vaughn (1992), Okamoto and Smith-Lovin (2001), Sukrutrit (2010), and Jeon (2012).

The remainder of this paper is structured as follows. Section 2 provides an overview of the research on the notions of topic, topic maintenance, and topic transition. Section 3 describes the data used in the study and how it was transcribed. Section 4 presents and discusses the main findings of the study. Section 5 concludes the discussion.

\section{Literature Review}

Many researchers refer to 'topic' as the subject on which people talk. For example, Porhiel (2005) defines topic as what the interaction is about, while Chafe (1994, p. 128) refers to topic as "the totality of information that is semi-active at one time." Seedhouse (2004, p. 38) elaborates that "topic is a central concept in the analysis of talk and is co-constructed by participants during the course of the talk." According to Okamoto and Smith-Lovin (2001, p. 853), topics are established as speakers pursue, elaborate, and shape them. Speakers are in constant competition to hold and take the floor and may control what is being discussed (De la Croix, 2010).

Regarding topic maintenance, Goffman (1983), Radford and Tarplee (2000), Abu Akel (2002), Sukrutrit, (2010), and Jeon (2012) distinguish between different techniques employed by speakers to exhibit attentiveness and 
understanding of the prior utterance and to stay on topic. The techniques are minimal responses, substitutions, and deletions. Minimal responses such as "mmm", "yeah", and "okay" bear no critical meaning, but they invite the speaker to keep on talking about the topic-in-progress. By avoiding repeating the same utterance as the speaker's prior turn, a speaker may use anaphoric references such as pronouns, thus showing interest in the topic at hand. Fulfilling the same purpose, a speaker can also use deletion in his/her turn; in such case, his or her turn becomes relevant to the context of the previous conversation.

Topic transition occurs when an utterance does not show a clear referential relationship to the prior talk (West \& Garcia, 1988; Ainsworth-Vaughn, 1992; Svennevig, 1999; Stokoe, 2000; Okamoto \& Smith-Lovin, 2001; Sukrutrit, 2010; Jeon, 2012). A topic transition "restores smooth speaker transition, [providing] a solution to the problem" (Okamoto \& Smith-Loving, 2001, p. 853). In terms of types of topic transition, West and Garcia (1988), Sukrutrit (2010), and Jeon (2012) differentiate between two types of topic transition, namely collaborative and unilateral. Collaborative topic transitions take place when the participants collaborate to close down the topic. Unilateral topic transitions are when one participant one-sidedly changes the topic without the cooperation of other participants in a conversation. Furthermore, Ainsworth-Vaugh (1992) and Okamoto and Smith-Lovin (2001), distinguish three subtypes within unilateral topic transitions: linked, minimally linked, and sudden. Linked unilateral topic transitions suggest that the speaker in the same turn acknowledges the ongoing topic before shifting to a new topic. In sudden topic transitions, however, the speaker never responds to the ongoing topic. Minimally linked unilateral topic transitions are when the speaker uses markers such as "all right" and "yeah" before starting a new topic.

\section{Data Collection and Transcription}

The data were gathered from a 21-minute dyadic, face-to-face, mundane English dinnertime conversation between a couple, a boyfriend and girlfriend. The couple is in their late twenties and are native speakers of English living in Bloomington, IN. In the session, the conversation was videotaped inside the participants' apartment to reduce any background noise. Next, the conversation was transcribed following the extensive transcription system developed by Jefferson (2004). The notations used in the transcription are listed in Table 1 .

Table 1. Transcription conventions

\begin{tabular}{ll}
\hline Symbol & Use \\
\hline$\rightarrow$ & Target line referred to in the text \\
{[]} & Overlapping speech \\
$=$ & Contiguous speech \\
$()$. & Brief pause \\
$\uparrow$ & Rising intonation \\
$\downarrow$ & Falling intonation \\
$\circ$ & Whispered speech \\
underline & Stressed speech \\
, & Temporary rise or fall in intonation \\
$::$ & Prolonged utterance \\
$/ \mathrm{T} /$ & Topic transition \\
$(($ text $))$ & Non-verbal activity \\
() & Unclear speech \\
\hline
\end{tabular}

\section{Results and Discussion}

\subsection{Topic Maintenance}

In excerpts 1, 2, and 3, the speakers demonstrate focus and understanding in taking multiple turns that are related to the same topic by using minimal responses, substitutions, and deletions, respectively.

Excerpt: (1)

$\mathrm{A}=$ The female speaker, $\mathrm{B}=$ The male speaker

The conversation is about the pictures of their cat (Phattie) that is being shown to one of their friends.

058. A: The pictures I showed him were the ones of Phattie, where she was 059. laying in the corner.

060. $\rightarrow$ B: Mmmm.

061. A: She really does look big. 
062. B: Hahaha.

063. A: (pause) But the dim sum place?

064. B: Uh-mm.

065. A: OK, how much do you think we spent after all the stuff I told you we

066. ordered?

In excerpt 1, Speaker (A) talks to Speaker (B), in lines 058 and 059 about showing their cat's pictures to one of their friends. In line 060, Speaker (B) uses the minimal response "Mmmm" to demonstrate understanding and attentiveness to what Speaker (A) is saying. Not only that, but Speaker (B) also uses this marker to encourage Speaker (A) to stay on topic (line 061).

The second technique used by the speakers to show an understanding of a prior turn in a conversation is substitution. This can be done by using anaphors (mainly pronouns) to refer to entities introduced by the previous speaker in the previous turn. For example, as illustrated in excerpt (2) below, Speaker (B) uses the pronoun "it" in line 225 to tie his utterance to "the camera" presented in Speaker (B)'s prior turn (line 224).

Excerpt: (2)

$\mathrm{A}=$ The female speaker, $\mathrm{B}=$ The male speaker

The speakers are discussing if the camera can pick up Speaker (B)'s voice after he changed his place.

222. A: No are you sure? Why are you going over there?

223. B: Well you just need the conversation, right?

224. A: Yeah, but I don't know if the camera will pick you up over there.

225. $\rightarrow$ B: yeah, you will. It's got a good mike.

In the third technique, a speaker may demonstrate attentiveness to the running topic by using deletions. In excerpt (3), for example, Speaker (B) is positive that Gryffindor is a griffin (line 262). Speaker (A) maintains the same discussion in the following turn (line 263) by asking if Speaker (B) is sure that Gryffindor is the same lion they have argued about in a previous context (lines 244-252, see Appendix A). By exhibiting her understanding of the prior turn, Speaker (A) makes her utterance intelligible only with reference to a previous context.

Excerpt: (3)

$\mathrm{A}=$ The female speaker, $\mathrm{B}=$ The male speaker

The argument is about Ravenclaw and Gryffindor (characters in Harry Potter).

260. B: Wasn't Ravenclaw called Raven?

261. A: I don't know.

262. B: I am sure Gryffindor though is a griffin. [ ].

263. $\rightarrow$ A: [ are you sure that he is that lion?]

264. B: 'I'm gonna check right now. ${ }^{\circ}$

In sum, the speakers employ minimal responses, substitutions, and deletions to show an understanding of the previous turn in the conversations, thus signaling the ongoing development of the same topic. The lack of the above three techniques results in the shift to a new topic, as shown in the excerpts in the following section.

\subsection{Topic Transitions}

After the analysis of the structural features of topic transitions used by the couple in the 21-minute conversation, the types of topic transitions identified are West and Garcia's (1988), Sukrutrit's (2010), and Jeon's (2012) collaborative and unilateral topic transitions and Ainsworth-Vaughn's (1992) and Okamoto and Smith-Loving's (2001) linked, minimally linked, and sudden topic transitions. Each type is exemplified below using excerpts from the data.

\subsubsection{Collaborative Topic Transitions}

According to West and Garcia (1988), collaborative transition refers to the process in which both speakers cooperate to close an ongoing topic and start a new one. As shown in excerpt 4, Speakers (A) and (B) collaborate to end the current topic (line 234), agree to the ending (lines 235-236), and then start a new topic (line 237) by exchanging markers such as "yeah" and "okay." This exchange establishes an opportunity for Speaker (B) to 
move to a new topic of conversation (indicated by "/T/").

\section{Excerpt: (4)}

$\mathrm{A}=$ The female speaker, $\mathrm{B}=$ The male speaker

The conversation is about Speaker (A) offering socks to her boyfriend (Speaker B).

231. A: Okay, can I give you socks too?

232. B: No.

233. A: What? No. Okay.

234. A: Why don't you want socks? Are you sure?

235. B: Yeah.

236. A: Okay.

237. $\rightarrow$ B: /T/ Which, which (.) house is it again from Harry Potter?

Another example of a collaborative topic transition is also noted when both speakers are engaged in summarizing activities to end the current topic, therefore, giving the possibility for a topic shift (Ainsworth-Vaughn, 1992). Excerpt 5 line 146 demonstrates how Speaker (A) summarizes the running topic (i.e., Target's opening hours) for Speaker (B). Immediately in line 147, Speaker (B) confirms Speaker (A)'s turn (summary) and thereby provides Speaker (A) with the opportunity to change the topic (line 148).

\section{Excerpt: (5)}

$\mathrm{A}=$ The female speaker, $\mathrm{B}=$ The male speaker

Speaker (B) is not sure about the opening hours of the Target shopping center.

144. A: You're okay?

145. B: Hum, hum (.) I thought Target was closed on Sunday.

146. A: I think it closes at night at eight. Something like that ((she looks at her watch)).

147. B: I think at around eight.

148. $\rightarrow$ A: /T /Are you going ba::ck to work tomorrow?

149. B: Yea::h I probably should.

A third example of collaborative topic transition is coordinated through the silence of the speakers (West \& Garcia, 1988). As illustrated in excerpt (6) below, the current topic is terminated, and then the topic shift takes place immediately after the pause (line 283). According to Maynard (1980, p. 265), when pauses occur in turn, topic shifts are instigated as a means to solve the problem of "the transfer of speakership." The lack of any contribution by Speaker (B) coupled with a longer silence between the two speakers invites Speaker (A) to change the topic-in-progress to another different topic (i.e., the story of Kathy wanting Speaker (A)'s bag).

Excerpt: (6)

$\mathrm{A}=$ The female speaker, $\mathrm{B}=$ The male speaker

Speakers (A) and (B) argue about the original colors of Ravenclaw and Hufflepuff (characters in Harry Potter).

278. A: Oh, anyway, I think that is Ravenclaw (.) Hufflepuff I know for sure is=

279. = purple and silver (.) Ravenclaw might be gold (.) no no (.) silver and blue.

280. B: Yeah, I think that is right.

281. A: NO, it is gold and blue. I think that the movie changed it to silver and blue=

282. $=($.$) Yeah (.) I think so.$

283. $\rightarrow$ A: (( drinks)) ( pause) / T/ $\uparrow$ Kathy really wants my bag.

\subsubsection{Unilateral Topic Transitions}

As defined earlier, unilateral topic transitions refer to the one-sided introduction of a new topic by one speaker, without the running topic being ended collaboratively by both speakers. As highlighted by Ainsworth-Vaughn (1992) and Okamoto and Smith-Loving (2001), there are three types of unilateral topic transitions attested in the data: linked, minimally linked, and sudden. 
Concerning the linked unilateral topic transitions, one speaker refers to the current topic before closing it and starting a new one in the same turn. This is demonstrated in excerpt (7) where Speaker (A) expresses her concern to Speaker (B) that she has forgotten to buy his ticket. Answering Speaker (B)'s "did you?" with "yeah" (line 318), Speaker (A) moreover affirms, in line 319, that she will do something to buy the tickets, before she immediately changes the whole topic of the conversation to another topic, namely her French paper. It is noteworthy that this linked transition is regarded as unilateral since Speaker (B) might still have some questions pertinent to the old topic (i.e., the ticket).

\section{Excerpt: (7)}

$\mathrm{A}=$ The female speaker, $\mathrm{B}=$ The male speaker

Speaker (A) tells Speaker (B) that she has forgotten to buy his tickets.

316. A: ((drinks)) hhh (.) I forgot to buy your ticket today.

317. B: ${ }^{\circ}$ did you?

318. A: Yeah.

319. $\rightarrow$ A: ((drinks) I'll call them. (.) /T/ I have to write a French paper, (.) 'cause it's due.

320. B: [why?]

The second type of unilateral topic transition is a minimally linked transition in which a speaker uses minimal responses such as "yeah," "okay," and "all right" before non-collaboratively shifting to a new topic (hence, a unilateral transition). As shown in excerpt (8) below, in line 254 Speaker (A) acknowledges Speaker (B)'s prior turn by employing "okay" (the minimal link), but she next moves to a new discussion by posing a question irrelevant to the topic at hand. It is worth adding that the use of "okay" in this instance, unlike in topic maintenance, is never meant to encourage the speaker to elaborate on the topic-in-progress.

Excerpt: (8)

$\mathrm{A}=$ The female speaker, $\mathrm{B}=$ The male speaker

The speakers here are hotly debating what a griffin is.

251. B: That is what a griffin is.

252. A: Are you sure it is a griffin?

253. B: Yeah or else they would be called Gryffindor.

254. $\rightarrow$ A: Okay. /T/ Why have you called Hufflepuff a badger?

255. B: Well, what is a Hufflepuff?

The third type of unilateral topic transition is a sudden transition. As discussed by Ainsworth-Vaughn (1992), a topic transition is considered sudden when a speaker does not acknowledge the current topic before starting a new topic. In excerpt (9), the discussion about Hufflepuff is terminated because in line 260, Speaker (B) suddenly and with no acknowledgment of Speaker A's previous utterance (line 259) makes a sudden topic change by asking an unrelated question. This topic transition prevents the development of the current topic (about Hufflepuff) (lines 256-259) and instead signals a shift to a different topic (about Ravenclaw).

\section{Excerpt: (9)}

$\mathrm{A}=$ The female speaker, $\mathrm{B}=$ The male speaker

The two speakers are engaged in discussing what a Hufflepuff is.

256. B: Well, what's a Hufflepuff?

257. A: What? Exactly (.) [Hufflepuff] is the name of the house (.) remember all=

258. B: ${ }^{\circ}[\text { yeah }]^{\circ}$

259. A: $=$ The houses (.) are named after a person (.) Godric Gryffindor.

260. $\rightarrow$ B: /T/ Wasn't Ravenclaw called raven?

\section{Conclusion}

This study examined the dynamics of two conversational phenomena, topic maintenance and topic transition, in a 21-minute dyadic dinnertime conversation between an American couple (a boyfriend and girlfriend) in their late twenties. In particular, the focus was placed on the pattern speakers use to maintain the conversation on the 
topic-in-progress and the features they employ to close the topic-in-progress and start a new topic. It is evident in the analyzed data that the speakers used three strategies to achieve topic maintenance and demonstrate their understanding of the prior turn. These strategies are minimal responses, substitutions, and deletions (Goffman, 1983; Radford \& Tarplee, 2000; Abu Akel, 2002; Sukrutrit, 2010; Jeon, 2012). With respect to topic transitions, different types were evident in the data, namely West and Garcia's (1988), Sukrutrit's (2010), and Jeon's (2012) collaborative and unilateral topic transitions and Ainsworth-Vaughn's (1992) and Okamoto and Smith-Lovin's (2001) linked, minimally linked, and sudden topic transitions. Once made, these types of topic transitions mark the termination of an old topic and the initiation of a new one.

\section{Acknowledgments}

The author would like to thank both the Deanship of Scientific Research and the College of Arts Research Center at King Saud University for funding this research project.

\section{References}

Abu Akel, A. (2002). The psychological and social dynamics of topic performance in family dinnertime conversation. Journal of Pragmatics, 34, 1787-1806.https://doi.org/10.1016/S0378-2166(01)00054-6

Ainsworth-Vaughn, N. (1992). Topic transitions in physician-patient interviews: Power, gender and discourse change. Language in Society, 21, 409-426. https://doi.org/10.1017/S0047404500015505

Brown, G., \& Yule, G. (1983). Discourse analysis. Cambridge: Cambridge University Press. https://doi.org/10.1017/CBO9780511805226

Chafe, W. (1994). Discourse, consciousness, and time: The flow and displacement of conscious experience in speaking and writing. Chicago: University of Chicago Press.

De la Croix, A. (2010). The language game of role-play: An analysis of assessed consultations between third year medical students and simulated patients (SPs). Unpublished doctoral dissertation, The University of Birmingham, Birmingham, UK.

Goffman, E. (1983). Felicity's condition. American Journal of Sociology, 89, 1-53. https://doi.org/10.1086/227833

Holt, E., \& Drew, P. (2005). Figurative pivots: The use of figurative expressions in pivotal topic transitions. Research on Language \& Social Interaction, 38(1), 35-61. https://doi.org/10.1207/s15327973rlsi3801_2

Jefferson, G. (2004). Glossary of transcript symbols with an introduction. In G. H. Lerner (Ed.), Conversation analysis: Studies from the first generation (pp. 13-31). Amsterdam, The Netherlands: John Benjamins Publishing. https://doi.org/10.1075/pbns.125.02jef

Jeon, S. (2012). Management of topics in online one-to-one English conversation instruction: A micro-analytic investigation of computer-mediated communication. Unpublished doctoral dissertation, Newcastle University, Newcastle, UK.

Li, C., \& Thompson, S. (1976). Subject and topic: A new typology of language. In C. N. Li (Ed.), Subject and topic (pp. 457-489). New York, NY: Academic Press.

Maynard, D. (1980). Placement of topic changes in conversation. Semiotica, 30, 263-290. https://doi.org/10.1515/semi.1980.30.3-4.263

Okamoto, D. G., \& Smith-Lovin, L. (2001). Changing the subject: Gender, status, and the dynamics of topic change. American Sociological Review, 66, 852-873. https://doi.org/10.2307/3088876

Porhiel, S. (2005). Les marqueurs de thématisation: Des thèmes phrastiques et textuels. Travaux de Linguistique, 51, 55-84. https://doi.org/10.3917/tl.051.0055

Radford, J., \& Tarplee, C. (2000). The management of conversational topic by a 10-year old child with pragmatic difficulties. Clinical Linguistics and Phonetics, 14(5), 387-403. https://doi.org/10.1080/02699200050051092

Roberts, C. (2011). Topic. In C. Maienborn, K. Von Heusinger \& P. Portnerand (Eds.), Semantics: An international handbook of natural language meaning (vol. 2, pp. 1908-1934). Berlin, Germany: Walter de Gruyter.

Schegloff, E. (1979). The relevance of repair to syntax-for-conversation. In T. Givón (Ed.), Syntax and semantics 12: Discourse and syntax (pp. 261-288). New York, NY: Academic Press.

Schegloff, E., \& Sacks, H. (1973). Opening up closings. Semiotica, 7, 289-327. 
https://doi.org/10.1515/semi.1973.8.4.289

Seedhouse, P. (2004). The interactional architecture of the language classroom: A conversation analysis perspective. Malden, MA: Blackwell Publishing.

Sidnell, J. (2010). Conversation analysis: An introduction. Chichester: Wiley. https://doi.org/10.1093/obo/9780199772810-0062

Stokoe, E. H. (2000). Constructing topicality in university students' small-group discussion: A conversation analytic approach. Language \& Education, 14(3), 184-203. https://doi.org/10.1080/09500780008666789

Sukrutrit, P. (2010). A study of three phases of interaction in synchronous voice-based chatrooms. Unpublished doctoral dissertation, Newcastle University, Newcastle, UK.

Svennevig, J. (1999). Getting acquainted in conversation: A study of initial interactions. Amsterdam, The Netherlands: John Benjamins. https://doi.org/10.1075/pbns.64

West, C., \& Garcia, A. (1988). Conversational shift work: A study of topical transitions between men and women. Social Problems, 35, 550-575. https://doi.org/10.2307/800615

Zellers, M. (2013). Prosodic variation for topic shift and other functions in local contrasts in conversation. Phonetica, 69(4), 231-253. https://doi.org/10.1159/000353445

\section{Appendix A}

\section{Transcribed Conversation}

001. A: [Hahaha.]

002. B: [Hahaha.]

003. A: Yeah. Is that OK?

004. B: Yeah.

005. A: You could say "hi" if you want.

006. B: ((waves at camera))

007. A: ((waves at camera)) If you can’t finish just lemme know.

008. B: Sure.

009. A: D'you feel funny?

010. B: Uh-uh.

011. A: Hahaha. I do.

012. B: It's funny though.

013. A: ((takes a bite of food)) (pause) I have to agree. How's the dan tat?

014. B: Really good.

015. A: I thought it was a little weird though.

016. B: ((smiles)) What's weird?

017. A: (pause) Oh, I thought the-hahaha. I thought the dan tat was.

018. B: (pause) Was it different?

019. A: [Hahaha.]

020. B: [Hahaha.]

021. A: Wasn't it?

022. B: No, is that what you meant by weird?

023. A: Yeah.

024. B: (pause) Why? Cause they're bigger?

025. A: I don't know. They tasted a little different too.

026. B: Mm. Tasted good [though.] 
027. A: [But-but], I think it's just-just that I remembered them

028. being creamier?

029. B: Mm.

030. A: At least in [Hong Kong.]

031. B: [And the crust is thicker] in Hong Kong.

032. A: Yea::h. ((takes a bite)) (pause) I miss the crust. I told Matt and Cathy that

033. they had it at KFC (short pause) in Hong Kong.

034. B: [Uh-hm.]

035. A: [They thought] that was pretty weird.

036. B: With the maple syrup [in 'em.]

037. A: [Yea:h.] I told 'em too, and then (pause) Matt got

038. really excited about that.

039. B: (pause) How come Cathy doesn't like it?

040. A: I don’t know. Cathy always order Mapo Tofu without pork.

041. B: Haha.

042. A: Always. ((takes a bite)) Hey, baby $\uparrow$ ((looks back toward the floor))?

043. (pause) But, I don't know why.

044. B: ((looks back toward the floor)) Hi, baby $\uparrow$.

045. A: She did get really fat.

046. B: ((looks back toward the floor)) You're fat, Phattie.

047. A: Hahaha. Brian said (h) that he told Cathy (h) that she's never looked

048. bigger. [That she's huge as ever.]

049. B: [Really?]

050. A: You [know-.]

051. B: [But how does Brian know?]

052. A: [Um, um.]

053. B: [The pictures you sent?]

054. A: [Yeah.] Cause he saw the pictures on the camera of

055. Phattie. (pause) You know at the wedding ((smiles)). I had to stop him

056. from going through.

057. B: ((nods))

058. A: The pictures I showed him were the ones of Phattie, where she was laying

059. in the corner.

060. B: Uh-hm.

061. A: She really does look big.

062. B: Hahaha.

063. A: (pause) Mm, but the dim sum place?

064. B: Uh-hm.

065. A: OK, how much do you think we spent after all the stuff I told you we

066. ordered?

067. B: (pause) Let's see. (short pause) Five of you.

068. A: Uh-hm. 
069. B: Thirty buck.

070. A: ((raises eyebrows))

071. B: Fifty buck.

072. A: ((raises eyebrows))

073. B: A hundred?

074. A: Fifty-eight buck.

075. B: ((nods)) That's not that good.

076. A: I know but-

077. B: Even for five people, it's not that good.

078. A: I know. That's what stinks. Cause we ((takes a bite)). Mm. I think the

079. Cantonese noodles [were expensive-]

080. B: [Uh-hm.]

081. A: Cause that was [like a special thing.]

082. B: [That wasn't part of the dim sum.]

083. A: Right. But we got two orders of the dan tat, uh, spring roll, and sesame

084. balls. I wonder if that's what put it over the edge.

085. B: ((nods))

086. A: (pause) But at least there's a place we can get dim sum, but I think it's just

087. so expensive cause it's Indiana.

088. B: Mm.

089. A: [But it was pretty good-.]

090. B: ((looks back toward the floor)) [Hey, Phattie $\uparrow$.$] You wanna come up$

091. here? Hehehe.

092. A: (pause) While you were sleeping, though, she musta been really hungry.

093. Cause I gave her the milk from my cereal.

094. B: Uh-hm.

095. A: But she tried to get your chicken noodle soup.

096. B: Hehe

097. A: I told you how I swatter her away right?

098. B: ((touches forehead))

099. A: You OK?

100. B: Yeah, just to see if it broke.

101. A: ((touches his forehead)) No, not yet. Come 'ere.

102. A \& B: ((touch foreheads))

103. A: Not yet. ((coughs)) But that should warm you up to ((points to soup)).

104. (pause) I hope. (pause) This turned out pretty good.

105. B: It's delicious.

106. A: I'm sorry there's so much. I know that's all you've been eating lately.

107. B: Hehehe

108. A: [Hey, you wanna go for a ride later?]

109. B: [It's delicious, though.] Yeah, sure.

110. A: Hm? You feel up for it? 
111. B: Uh-hm:

112. A: (pause) When did you start to feel better?

113. B: I don't know now if I (h) do feel better or not.

114. A: Really?

115. B: When I started gettin' up and walkin' around. Felt the same.

116. A: Oh, you mean it-it's as bad as before?

117. B: ((nods))

118. A: ((takes a bite)) Mm:

119. (long pause)

120. How do you feel now?

121. B: ((smiles)) Feel better. I'm not sure if it's the medicine or not.

122. A: ((smiles)) Oh yeah?

123. B: ((smiles)) Yeah.

124. A: [Hahaha.] Oh yeah, I gotta go take books back to the library too.

125. B: Tonight?

126. A: Yeah. I think a bunch are due (h). And I put 'em all in the car, though.

127. Wanna ride with me for that?

128. B: Uh-hm.

129. A: You wanna go anywhere? I'll take you for ice cream. I don't know if

130. that'd be good for you, never mind.

131. B: Hehehe.

132. A: ((takes a bite)) (pause) Unless you want it.

133. B: Sure.

134. A: Really $\uparrow$ ? You want lemon custard?

135. B: Okay.

136. A: Hm?

137. B: That sounds good.

138. A: ((looks in bowl)) You want my chicken skin?

139. B: Uh-hm.

140. A: Really $\uparrow$ ?

141. B: Uh-hm.

142. A: OK ((gives food)).

143. B: Hm-hm.

144. A: Here you go, baby. Do you feel better or worse than you did in the very beginning, though?

145. B: Better.

147. A: Really $\uparrow$ ? Good.

148. B: Phattie, what are you lookin at ((looks back toward floor))?

149. A: ((looks back toward floor)) Youwant to comere? Want some chicken?

150. B: ((looks back toward floor))

151. A: I don't think she likes chicken soup, though. (pause) I'll tryda giver a little.

152. Here, should we try?

153. B: Uh-hm. 
154. A: ((hands food to cat)) Think she'll eat it?

155. B: Is it chicken?

156. A: Yeah?

157. B: ${ }^{\circ} \mathrm{Oh}$ no, you better eat that. ${ }^{\circ}$ Did she eat it?

158. B: Uh-uh. ((Speaks to cat)) Was it good, though? Hm? Hehe.

159. A: I'm pretty sad. OK.

160. B: Hehe.

161. A: Phattie. ((speaks to cat)) Go on if you don't want it. Well, at least now we

162. know-I think she thinks everything you eat in a bowl, is cereal.

163. B: ((nods)) Mm.

164. A: I'm pretty sad.

144. A: you're okay?

145. B: hum, hum (.) I thought target was closed on Sunday.

146. A: I think it closes at night at eight. Something like that ((she looks at her watch)). I

147. think at around eight; Why? Do you want to get something?

148. B:

149. A: Are you going ba::ck to work tomorrow?

150. B: Yea::h I probably should

151. A: (

152. B: Yeah, I asked him the day before.

153. A: Even if he came at 4.45 [I would have to be]

154. B: [I'm gonna ask him] if I can get up half an hour earlier.

155. A: Oh, $\uparrow$ really

156. B: hm, hm

157. A: hm

158. B: it should be no problem we are going to work at eight.

159. A: okay that would be perfect. And you just have your half hour lunch. I'll send you with

160. some chicken soup tomorrow.

161. B: sure

161. A: I'll put it in a thermos. Hm, hm

162. (.)

163. A: Is that a bone?

164. B: hm

165. A: I'm sorry

166. (13.0)

167. A: I'm sorry

168. B: Are we allowed to address the camera?

169. A: Yes (.) I don't see why not.

170. B: hm

171. A: $\uparrow$ hi camera

172. B: Chinese soup spoons. I can't:: live without them

173. A: Ha, ha You'::re crazy 
174. B: Ha, ha

175. A: That was awesome (.) hum ((she bangs the table)) I'm gonna make that blueberry

176. coffee cake tonight for tomorrow.

177. B: I know

178. A: Are you okay?

179. B: yeah

180. (9)

181. A: Hm. I'm gonna tell you. At the ( ) Place

182. People really seem to like Alex and Cathy. And you know when we went to that Thai

183. restaurant with them, they would come up to Alex and stuff. These women were

184. obsessed with Aubrey. Like they [I think one of them]

185. B: [she is a cute baby]

186. A: $<$ Yeah, she really is cute. $\uparrow$ And she likes me now. $\uparrow$ She gave me a hu::g and a ki::ss

187. when I left. It was so cute. Right before, "cause we had to run off so I went to her and I

188. was trying to run after her and Alex said Aubrey give me a hug and a kiss and he ran into

189. her and he gave her a hug and she hugged him back and then she, he kissed her on the

190. forehead.>

191. B: That's cute

192. A: $\uparrow$ That was so cute. And the last time they tried to do that they both fell over.

193. B: Ha ha ha

194. A: ha, ha. It really cracked me up. But, but yeah. >Aubrey $\uparrow$ she ga::ve me a hu::g and

195. she gave me a ki::ss and she likes to point to your nose $<$.

196. B: Does she talk yet?

197. A: Yeah, really little. Yeah, she $\uparrow$ says daddy, she $\uparrow$ says mama and she goes "wishies"

198. B: ha ha

199. A: And -

200. B: which is like a word?

201. A: yeah pretty much does like that. There was, he had the water and she is not picky at 202.all. She would eat or drink anything so Cathy would give her some water and she goes 203."wishies' and she pushed it away and she goes "wishies" and he was "do you want some 204. water?" and she goes "wishies". And he goes oh, that's the water sign, oh.

205. B: ha ha

2060. A: And then ha ha. He just put it down. It was very cu::te.

207. B: That's right

208. A: ( ) I've never seen him mad so

209. B: angry?

210. A: No he is on a very. Hm, he, he is on edge. Like his patience is going thin.

211. B: Is it that worse?

212. A: I'm not kidding. Like on Saturday, you know I wasn't, oh I was feeling so hot you

213. know. Every single thing that came out from Cathy to Alex was "come on, come on". Oh

214. men. Are you okay?

215. B: Yeah, yeah sure ((leaves the table)) 
216. A: Wait, wait, wait, wait NO.

217. (.)

218. A: What did I say? Why is the door going backwards?

219. B: It's fine ((he mumbles))

220. A: That's IT

221. B: Yeah, yeah, that's it

222. A: No Are you sure? Why are you going over there?

223. B: Well you just need the conversation right?

224. A: Yeah, but I don't know if we will be able to pick you up over there.

225. B: yeah, you will. It's got a good mike.

226. A: Now is it. Are you lying down or are you gonna play?

227. B: hm

228. A: IAN (.) IAN, are you going to lay down a bit? Where are you going? DON'T, NO,

229. NO, NO, NO. Go to the (

230. B: 'Cause I need my ( ) .

231. A: Okay can I give you socks too?

232. B: No

233. A: What? No. okay

234. A: Why don't you want socks? Are you sure?

235. B: Yeah

236. A: okay

237. (10)

238. B: Which, which (.) house is it again from Harry Potter?

239. (11)

240. B: Hufflepuff

241. A: It's not (3) Hufflepuff with the heather?

242. B: Can't remember.

243. A: Don't have any animal, right? No animal on it right

244. B: No, Gryffindor. With the lion.

245. A: Is it gryffin?

246. B: No Gryffin is with a gryffin (.) no just with a lion.

247. A: Is it gryffin?

248. A: it is not just that lion, (.) [ it is the flying] lion that has four quick wings.

249. B: [Is it a griffin?]

250. B: $\uparrow$ are you su:re?

251. A: that is what a griffin is

252. B: are you sure it is griffin?

253. A: yeah, or else they would be called Gryffindor.

254. B: why have you called hufflepuff a badger?

255. A: well, what's a hufflepuff?

256. B: what? Exactly (.) [hufflepuff] is the name of the house (.) remember all=

257. A: ${ }^{\circ}[\text { yeah }]^{\circ}$ 
258. $\mathrm{B}:=$ the houses $().[$ are named after a person](.) godric gryffindor

\section{A: ${ }^{\circ}$ [ yeah I know ${ }^{\circ}$}

260. A: wasn't ravenclaw called raven?

261. B: I don't know

262. $\rightarrow$ A: I am sure gryffindor though is a griffin.[

263. B: [Are you sure he is that lion?]

264. A: ${ }^{\circ} \mathrm{I} ' \mathrm{~m}$ gonna check right now.

265. B: OKAY, that'll work. ((going to kitchen))

266. B: I have a sweet-[

267. A: [I am sure it's a griffin].

268. B: Oh.

269. A: it's slithering like a snake.

270. B: yeah, what is slithering?

271. A: you know like slithering $\downarrow$ snakes-

272. B: but it is still(.) $\uparrow$ hufflepuff is a badger?

273. A: ${ }^{\circ}$ No::: ${ }^{\circ}$

274. B: ((laughs)) it is a badger, right?

275. A: I do not know.

$278 \rightarrow \mathrm{B}$ : Oh anyway I think that is ravenclaw $($.) hufflepuff I know for sure is=

279. $=$ purple and silver. (.)ravenclaw might be (.) gold (.) no no (.) silver and blue

280. A: Yeah I think that is right.

281. B: NO it is gold and blue. I think that the movie changed it to sliver and blue (.) yeah= 282. $=($.$) I think so.$

283. B: ((drinks)) mmm (.)个 Kathy really wants my bag.

284. A: which bag?

285. B: the little louis?

286. B: she asked again yesterday, $<$ she asked where was mine? $>$ ( ) I said oh ( $\quad$ ) in=

287. $=$ Hong Kong.

288. A: ${ }^{\circ}($

)$^{\circ}$

289. B: is that so?

290. A: Oh, it is the one from Honk Kong?

291. B: yeah (.) remember the lady (.)<That, oh, my canvas one. >

292. A: ${ }^{\circ}$ oh yeah yeah ${ }^{\circ}$

293. B: ((finishes drinking)) Alright.

294. A: you're done?

295. B: yeah (.) I am finished. (. ) ((checks the camera)) what does that say?(.) is that=

296. = really right?

297. A: what does it say?

298. B: only SEVEN minutes.

299. A: when'd you start it?

300. B: I can't remember (.) but we didn't eat that fast.... Did we?

301. A: (long pause) ${ }^{\circ}$ it is possible. ${ }^{\circ}$ 
302. B: ${ }^{\circ}$ I do not know ${ }^{\circ} \uparrow \mathrm{OH}$ HONEY!?

303. A: ${ }^{\circ}$ it is the tape time, right? ${ }^{\circ}$

304. B: yeah like it just went six minutes.

305. A: Oh okay (.) ${ }^{\circ}$ you can stop it. ${ }^{\circ}$

306. B: but now I am confused (.) because now I do not know how long it is.

307. A: It was five earlier, right?

308. B: but that went to seven and now it is six.

309. A: that is weird.

310. B: right?

311. B: I can’t be reading a six wrong, can I? (.) $\uparrow$ Crap!

312. A: I (.) I feel like (.) it's been fifteen, so-[

313. B: [did you finish your juice?]

314. A: Yeah. (long pause) why?

315. B: okay (.) I can't just remember which one was mine.

$316 \rightarrow$ B: ((drinks)) hhh (.) I forgot to buy your ticket today.

317. A: ${ }^{\circ}$ did you? ${ }^{\circ}$

318. B: Yeah.

$319 \rightarrow$ B: ((drinks)) I'll call them. (.) I have to write a French paper, (.) 'cause it is due. I = 320. A: [why?]

321. $\mathrm{B}:=$ do not think it is gonna be too hard though, (.) ((clears her throat)) but it has=

322. $=$ to be 4 pages.(.) Did I tell you already?

323. A: ${ }^{\circ}$ no.

324. B: 4 pages and it cant be double spaced. (.)it has to be 1.5 and we have to do it=

325. = right and left justified.

326. B: isn't that weird?(.) Isn't that weird? (.) it is weird.

327. B: what is that smell? (laughing) (.) did you?

328. A: no.

329. B: yes?

330. A: I did not (.) not really.

331. B: all right, ((laughs)) you know what's awesome (.) it's on ta:pe (continues laughing)= 332. $=(.)^{\circ}$ something stinks?

333. A: ${ }^{\circ}$ )$^{\circ}$

334. B: is it? (. $)^{\circ}$ maybe. ${ }^{\circ}$ (.) that is a possibility.

335. B: are you sure that this camera is gonna take you up?

336. A: Yeah.

337. B: all right.

338. A: it picked up our bad neighbors creaking.

339. B: ((does dishes)) yes $\uparrow$ that was super LOud.

340. B: all right (.) you want anything else?

341. A: no (.) not really.

342. B: okay.

343. B: ((checks the camera)) I am so confused. (.) OH YEAH it says three minutes now. 
344. $\rightarrow$ A: it is realian stuff.

345. B: what? (.)what do you do?

346. A: ((watches TV)) I don't know (.) it's-

347. B: ((watches TV) ${ }^{\circ}$ [that is so bad.]

348. A: I don't think he's really bad though.

349. B: really ba:d

350. B: but if he was a really crazy realian he'd just run through it.

351. B: ((watches TV)) OH, NO (.)<he's not even a realian, is he? >

352. A: he is a realian. $\downarrow$ He is-

353. B: how come he is okay?

354. A: Oh yeah, realians (.) they're wha- (.) they're a (.) heat (.) pr-(.) they're- (.) envi- = 355. $=($.$) environment proof$

356. B: $\uparrow$ WHAT?

$357 \rightarrow$ A: (long pause) they have heat tolerance and stuff like that.

358. B: did they just trick you?

359. A: that one, I think, isn't okay.

360. B: $\uparrow \mathrm{OH}$ man, that is crazy.

361. B: if that's a realian then that doesn't make sense.

362. B: ooh that is nice. (.) ((checks the camera)) Alright, it's got 2 minutes left. I will stop= 363. $=$ it. (.) do you wanna say goodbye?

364. A: good by::e.

365. B: ((waves at camera)) okay (.) by:e

\section{Copyrights}

Copyright for this article is retained by the author, with first publication rights granted to the journal.

This is an open-access article distributed under the terms and conditions of the Creative Commons Attribution license (http://creativecommons.org/licenses/by/4.0/). 